\title{
Intramedullary spinal cord ependymoma and astrocytoma: intraoperative frozen-section diagnosis, extent of resection, and outcomes
}

\author{
*Hiroki Hongo, MD, ${ }^{1}$ Keisuke Takai, MD, PhD, ${ }^{1}$ Takashi Komori, MD, PhD, ${ }^{2}$ and \\ Makoto Taniguchi, MD, PhD' \\ Departments of ${ }^{1}$ Neurosurgery and ${ }^{2}$ Laboratory Medicine and Pathology, Tokyo Metropolitan Neurological Hospital, Fuchu, \\ Tokyo, Japan
}

\begin{abstract}
OBJECTIVE The intraoperative differentiation of ependymomas from astrocytomas is important because neurosurgical strategies differ between these two tumor groups. Previous studies have reported that the diagnostic accuracy of intraoperative frozen sections of intracranial central nervous system (CNS) tumors is higher than $83 \%-97 \%$, whereas that for spinal intramedullary tumors remains unknown. Herein, authors tested the hypothesis that intraoperative frozen-section diagnosis is the gold standard for a differential diagnosis of intramedullary spinal cord tumors.

METHODS The clinical characteristics, intraoperative histological diagnosis from frozen sections, extent of tumor resection, progression-free survival (PFS), and overall survival (OS) of 49 cases of intramedullary spinal cord ependymomas $(n=32)$ and astrocytomas $(n=17)$ were retrospectively evaluated.
\end{abstract}

RESULTS The frozen-section diagnosis and final diagnosis with permanent sections agreed in $23(72 \%)$ of 32 cases of ependymoma. Of the 9 cases of ependymoma in which the frozen-section diagnosis disagreed with the final diagnosis, 4 were incorrectly diagnosed as astrocytoma and the other 5 cases had a nonspecific diagnosis, such as glioma. Nonetheless, gross-total resection was achieved in 6 of these 9 cases given the presence of a dissection plane. The frozensection diagnosis and final diagnosis agreed in $12(71 \%)$ of 17 cases of astrocytoma. Of the 5 cases of astrocytoma in which the frozen-section diagnosis disagreed with the final diagnosis, 1 was incorrectly diagnosed as ependymoma and the other 4 had a nonspecific diagnosis. Gross-total resection was achieved in only 1 of these 5 cases.

A relationship between the size of tumor specimens and the diagnostic accuracy of frozen sections was not observed. Ependymal rosettes and perivascular pseudorosettes were observed in 30\% and $57 \%$ of ependymomas, respectively, but were absent in astrocytomas.

Progression-free survival and OS were both significantly longer in cases of ependymoma than in cases of astrocytoma $(p<0.001)$. Gross-total resection was achieved in $69 \%$ of ependymomas and was associated with longer PFS ( $p=$ 0.041 ). In the astrocytoma group, gross-total resection was achieved in only $12 \%$ and there was no relationship between extent of resection and OS. Tumor grades tended to correlate with OS in astrocytomas $(p=0.079)$.

CONCLUSIONS The diagnostic accuracy of intraoperative frozen sections was lower for intramedullary spinal cord ependymomas and astrocytomas in the present study than that for intracranial CNS tumors reported on in the literature. Surgical strategies need to be selected based on multiple factors, such as clinical characteristics, preoperative imaging, frozen-section diagnosis, and intraoperative findings of the tumor plane.

https://thejns.org/doi/abs/10.3171/2018.7.SPINE18230

KEYWORDS intramedullary tumor; progression-free survival; overall survival; histopathology; tumor grade; surgical treatment; radiation; chemotherapy; oncology

ABBREVIATIONS CNS = central nervous system; GTR = gross-total resection; ISCT = intramedullary spinal cord tumor; OS = overall survival; PFS = progression-free survival; $P R=$ partial resection; STR = subtotal resection.

SUBMITTED February 28, 2018. ACCEPTED July 10, 2018.

INCLUDE WHEN CITING Published online October 19, 2018; DOI: 10.3171/2018.7.SPINE18230.

${ }^{*}$ H.H. and K.T. contributed equally to this study and share first authorship. 
$\mathrm{I}$ NTRAMEDULLARY spinal cord tumors (ISCTs) are relatively rare neoplasms that account for only $2 \%-4 \%$ of central nervous system (CNS) glial tumors. In adults, ependymomas are the most common ISCT, comprising approximately $50 \%-60 \%$ of ISCTs. ${ }^{2,3}$ Most ependymomas are slow growing and well demarcated from the spinal cord parenchyma. ${ }^{7}$ Accordingly, gross-total resection (GTR) is possible in most cases of ependymoma. Previous studies have reported that the extent of resection is a strong predictor of progression-free survival (PFS)., ${ }^{2,8}$, Intramedullary astrocytomas, the second most common ISCT, possess more infiltrative features than ependymomas., ${ }^{74}$ Because of this infiltrative characteristic, the relationship between GTR and PFS in astrocytoma is less clear, ${ }^{12}$ and adjuvant therapy such as radiotherapy and chemotherapy is often combined with resection. ${ }^{1,14}$ Since neurosurgical strategies differ between these two tumor groups, the differentiation of ependymoma from astrocytoma is important.

One method employed to differentiate the two tumor types is an intraoperative frozen-section diagnosis..$^{13,15}$ Previous studies have reported that the diagnostic accuracy of intraoperative frozen sections of intracranial CNS tumors is higher than $83 \%-97 \%, 3,4,13,15,16$ whereas that for ISCTs remains unclear. In the present study, we aimed to test the hypothesis that intraoperative frozen-section diagnosis is the gold standard for a differential diagnosis of ISCTs. Surgical cases of intramedullary spinal cord ependymomas and astrocytomas were reviewed in order to clarify how the results of a frozen-section diagnosis affect microsurgical treatments and outcomes.

\section{Methods}

\section{Patient Population and Clinical Data}

The present study was approved by the institutional review board at the Tokyo Metropolitan Neurological Hospital. All patients gave full written informed consent for frozen- and permanent-section diagnoses. Regarding study participation, written informed consent was not obtained because this was a retrospective study. A public notice that provided information on this study was instead provided by the Tokyo Metropolitan Neurological Hospital.

We retrospectively reviewed the medical records of 49 consecutive patients with intramedullary spinal cord ependymomas $(n=32)$ and astrocytomas $(n=17)$ for whom intraoperative frozen-section diagnoses were made at Tokyo Metropolitan Neurological Hospital between January 1993 and March 2016. Formalin-fixed paraffin-embedded sections were diagnosed based on the 2007 WHO classification of CNS tumors (Table 1). Ependymomas included WHO grade I subependymoma, grade II ependymoma, and grade III anaplastic ependymoma. Astrocytomas included WHO grade I pilocytic astrocytoma, grade II diffuse astrocytoma, grade III anaplastic astrocytoma, and grade IV glioblastoma. One recent case of diffuse midline glioma H3 K27M-mutant (WHO 2016) ${ }^{10}$ was classified as anaplastic astrocytoma in the statistical analysis. Cases of WHO grade I myxopapillary ependymomas were not included in this study because they can be differentiated from intramedullary ependymomas based on character-
TABLE 1. Subtype classification of ependymomas and astrocytomas

\begin{tabular}{crrrrr}
\hline \multirow{2}{*}{ WHO } & \multicolumn{2}{c}{ Ependymomas } & & \multicolumn{2}{c}{ Astrocytomas } \\
\cline { 2 - 3 } \cline { 5 - 5 } Grade & \multicolumn{1}{c}{ Type } & No. & & Type & No. \\
\hline I & Subependymoma & 3 & & Pilocytic astrocytoma & 2 \\
\hline II & Ependymoma & 28 & & Diffuse astrocytoma & 9 \\
\hline III & Anaplastic ependymoma & 1 & & Anaplastic astrocytoma & 5 \\
\hline IV & Not applicable & 0 & Glioblastoma & 1 \\
\hline
\end{tabular}

istic features on MRI. ${ }^{6}$ Patient demographics, symptoms, preoperative McCormick grades,${ }^{11}$ symptom duration prior to diagnosis, tumor location, tumor size, extent of resection, adjuvant therapy, follow-up period, recurrence/progression, and death were collected from medical charts. Tumor size was indicated by the number of vertebral bodies the tumor involved. Extent of excision was assessed on initial postoperative MRI and defined as follows: GTR, no residual tumor; subtotal resection (STR), 90\%-99\% resection; partial resection (PR), 5\%-89\% resection; and biopsy, $<5 \%$ resection. Recurrence and progression were defined as an increased tumor size on follow-up MRI. The median follow-up period was 70 months (range 1-252 months).

\section{Frozen-Section Diagnosis}

Diagnostic reports of a frozen-section diagnosis were classified into 1) agree, agreement between frozen-section and final diagnoses regardless of tumor grade; 2) disagree, no agreement between frozen-section and final diagnoses; and 3) nonspecific diagnosis, frozen-section diagnosis is too wide to be classified, i.e., glial tumors. Sensitivities, specificities, and positive and negative predictive values were calculated for the differentiation of ependymomas from astrocytomas.

In 36 cases ( 23 ependymomas and 13 astrocytomas), the presence of ependymal rosettes and perivascular pseudorosettes and the largest diameter of each specimen were re-reviewed using the surgical specimens for frozen sections. The relationship between the accuracy of the frozensection diagnosis and the maximum diameter of frozen sections was examined. In the remaining 13 cases, surgical specimens for frozen sections were not available.

At our hospital, the chief of the neuropathological department changed three times over a 23 -year study period; therefore, three experienced neuropathologists engaged in the pathological diagnosis of spinal intramedullary tumors. One of the three neuropathologists, a single neuropathologist, examined each frozen and permanent section. The relationship between the accuracy of the frozen-section diagnosis and each pathologist was examined.

\section{Preoperative MRI Diagnosis}

Diagnostic reports on the MRI were retrospectively reviewed in cases for which the frozen-section diagnosis disagreed with the permanent diagnosis. The MRI diagnosis had been performed prospectively prior to surgery by two experienced neuroradiologists. 
TABLE 2. Clinical, radiological, and therapeutic characteristics in patients with ependymomas and astrocytomas

\begin{tabular}{|c|c|c|c|}
\hline Variable & Ependymomas & Astrocytomas & p Value \\
\hline No. of patients & 32 & 17 & \\
\hline Age in yrs (range) & $47.5(26-79)$ & $43(1-84)$ & 0.081 \\
\hline No. of females & $16(50)$ & $10(59)$ & 0.76 \\
\hline \multicolumn{4}{|l|}{ Symptom } \\
\hline Pain & $21(66)$ & $10(59)$ & 0.76 \\
\hline Motor deficit & $21(66)$ & $16(94)$ & 0.037 \\
\hline Sensory deficit & $30(94)$ & $15(88)$ & 0.60 \\
\hline Bladder \& bowel & $11(34)$ & $6(35)$ & 1.0 \\
\hline Preop McCormick score & & & 0.057 \\
\hline 1 & $9(28)$ & $3(18)$ & \\
\hline II & $17(53)$ & $6(35)$ & \\
\hline III & $6(19)$ & $6(35)$ & \\
\hline IV & $0(0)$ & $2(12)$ & \\
\hline $\begin{array}{l}\text { Symptom duration in mos } \\
\text { (range) }\end{array}$ & $36(1-300)$ & $6(1-132)$ & 0.006 \\
\hline Lesion location & & & 0.64 \\
\hline Cervical & $21(66)$ & $10(59)$ & \\
\hline Thoracic & $11(34)$ & $7(41)$ & \\
\hline Lumbar & $0(0)$ & $0(0)$ & \\
\hline $\begin{array}{c}\text { Tumor size measured in ver- } \\
\text { tebral segments (range) }\end{array}$ & $2.5(1-8)$ & $4(1-11)$ & 0.022 \\
\hline Extent of resection & & & $<0.001$ \\
\hline GTR & $22(69)$ & $2(12)$ & \\
\hline STR & $7(22)$ & $1(6)$ & \\
\hline PR & $3(9)$ & $8(47)$ & \\
\hline Biopsy & $0(0)$ & $6(35)$ & \\
\hline Adjuvant therapy & & & 0.001 \\
\hline Radiotherapy alone & $3(9.4)$ & $4(24)$ & \\
\hline Chemo alone & $0(0)$ & $2(12)$ & \\
\hline Radiation \& chemo & $1(3.1)$ & $5(29)$ & \\
\hline None & $28(88)$ & $6(35)$ & \\
\hline
\end{tabular}

Values represent the median and range or the number of patients (\%). Boldface type indicates statistical significance.

\section{Statistical Analysis}

A Fisher exact test and Mann-Whitney U-test were used to statistically analyze the data obtained. Progression-free survival and overall survival (OS) were calculated with the Kaplan-Meier method. The JMP statistical software version 11.0.0 (SAS Institute Inc.) was used. A p $<0.05$ was considered to be significant.

\section{Results \\ Clinical Data}

Clinical, radiological, and therapeutic characteristics are summarized in Table 2. The prevalence of motor deficits was significantly lower in patients with ependymoma than in those with astrocytoma $(\mathrm{p}=0.037)$, although the duration of preoperative symptoms prior to a diagno-
TABLE 3. Frozen-section diagnosis and final histopathology

\begin{tabular}{lccc}
\hline \multirow{2}{*}{$\begin{array}{c}\text { Frozen-Section } \\
\text { Diagnosis }\end{array}$} & \multicolumn{2}{c}{ Final Permanent-Section Diagnosis } & Total \\
\cline { 2 - 3 } & Ependymoma & Astrocytoma & No. \\
\hline Ependymoma & 23 & 1 & 24 \\
\hline Astrocytoma & 4 & 12 & 16 \\
\hline Nonspecific diagnosis & 5 & 4 & 9 \\
\hline Total no. & 32 & 17 & 49 \\
\hline
\end{tabular}

sis was significantly longer for ependymoma cases $(\mathrm{p}=$ 0.006 ). Tumor sizes were smaller for ependymomas than for astrocytomas $(p=0.022)$. In 29 of 32 cases of ependymoma, GTR (22 cases [69\%]) or STR (7 cases [22\%]) was achieved; in only 3 of 17 cases of astrocytoma, GTR (2 cases [12\%]) or STR (1 case [6\%]) was achieved (p < 0.001 ). Adjuvant therapies were performed more frequently for astrocytomas $(\mathrm{p}=0.001)$.

\section{Frozen-Section Diagnosis}

The frozen-section diagnosis and final permanent-section diagnosis agreed in 23 (72\%) of 32 cases of ependymoma (Table 3). Gross-total resection was achieved in 16 (70\%) of these 23 ependymoma cases because of the presence of a dissection plane. Of the 9 ependymoma cases in which the frozen-section diagnosis disagreed, 4 were incorrectly diagnosed as astrocytoma (Fig. 1) and the other 5 had a nonspecific diagnosis; however, GTR was achieved in $6(67 \%)$ cases because of the presence of a dissection plane (Table 4). In only 1 case of ependymoma (Fig. 1) for which the frozen-section diagnosis was astrocytoma was the surgery stopped based on the intraoperative diagnosis. According to the final diagnosis of ependymoma, surgery was performed again and GTR was achieved.

The frozen-section diagnosis and final diagnosis agreed in 12 (71\%) of 17 cases of astrocytoma. Surgery was stopped based on the intraoperative diagnosis in 11 of the 12 astrocytoma cases for which the frozen-section diagnosis agreed: 5 cases resulted in biopsy and 6 in PR. Of the 5 cases of astrocytoma in which the frozen-section diagnosis disagreed, 1 was incorrectly diagnosed as ependymoma (Fig. 2) and the other 4 had a nonspecific diagnosis. Gross-total resection was achieved in only 1 case $(20 \%)$ of astrocytoma because of the absence of a dissection plane. In only 1 case of astrocytoma for which the frozen-section diagnosis was ependymoma was surgery continued for total removal; however, it resulted in only partial removal because of the absence of a dissection plane.

As shown in Table 3, sensitivity for the differentiation of ependymomas from astrocytomas was $72 \%$ (23/32), specificity was $71 \%$ (12/17), positive predictive value was $96 \%$ $(23 / 24)$, and negative predictive value was $75 \%(12 / 16)$. Ependymal rosettes were observed in 7 cases $(30 \%)$ of ependymoma (Fig. 3). Perivascular pseudorosettes were observed in 13 cases (57\%) of ependymoma and were associated with agreement between frozen-section and final diagnoses $(\mathrm{p}<0.001)$. The diameter of frozen sections was a median of $2.5 \mathrm{~mm}$ (range $0.9-16 \mathrm{~mm}$ ). A correlation was not observed between size of tumor specimens and accu- 
Hongo et al.
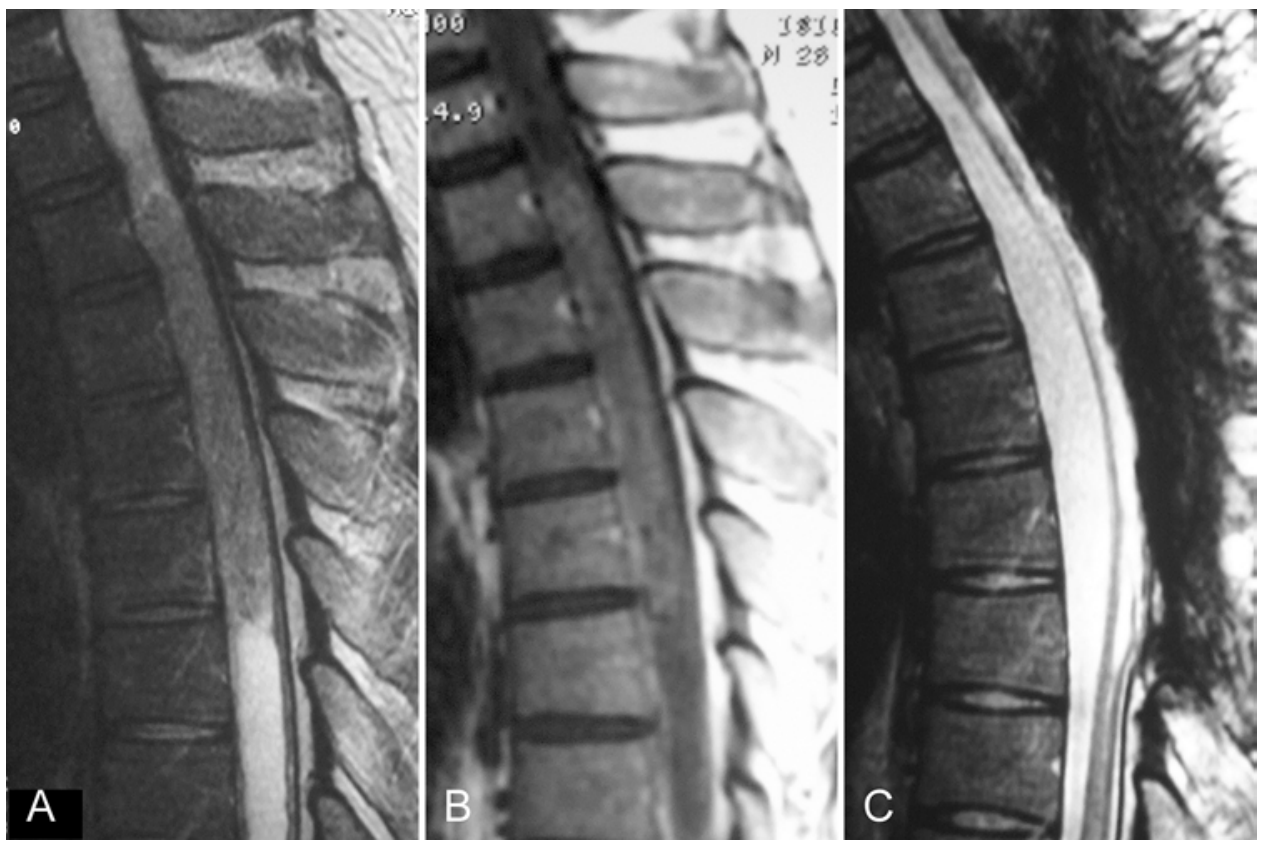

FIG. 1. Ependymoma misdiagnosed as astrocytoma using frozen sections. A 28-year-old man presented with a 2-year history of back pain and a 1-year history of progressive paraparesis. Sagittal T2-weighted MR image (A) showing an intramedullary mass at the T2-5 levels, with large cysts above and below the mass lesion. Gadolinium-enhanced T1-weighted MR image (B) showing enhancement of the mass. The radiological diagnosis included glial tumor, astrocytoma, and ependymoma. The intraoperative frozen-section diagnosis was astrocytoma. Since the spinal cord was swollen and edematous and the dissection plane was poorly defined, surgery was stopped after the frozen-section diagnosis, resulting in PR. Based on the final diagnosis of ependymoma, reoperation was performed. Postoperative T2-weighted MR image (C) showing GTR of the tumor.

TABLE 4. Summary of data for patients with spinal ependymomas and astrocytomas in whom the frozen-section diagnosis disagreed with the final diagnosis

\begin{tabular}{|c|c|c|c|c|c|c|c|c|c|c|}
\hline \multicolumn{2}{|c|}{ Final Permanent-Section Diagnosis } & \multirow[b]{2}{*}{$\begin{array}{l}\text { Frozen-Section } \\
\text { Diagnosis }\end{array}$} & \multirow{2}{*}{$\begin{array}{c}\text { Age } \\
(y r s) / \\
\text { Sex }\end{array}$} & \multirow[b]{2}{*}{$\begin{array}{l}\text { McCormick } \\
\text { Grade }\end{array}$} & \multirow[b]{2}{*}{$\begin{array}{l}\text { Tumor } \\
\text { Level }\end{array}$} & \multirow[b]{2}{*}{$\begin{array}{l}\text { Tumor } \\
\text { Size* }\end{array}$} & \multirow[b]{2}{*}{$\begin{array}{l}\text { Preop MRI } \\
\text { Diagnosis }\end{array}$} & \multirow[b]{2}{*}{$\begin{array}{l}\text { Extent of } \\
\text { Resection }\end{array}$} & \multirow[b]{2}{*}{ Recurrence } & \multirow[b]{2}{*}{ Outcome } \\
\hline $\begin{array}{l}\text { WHO } \\
\text { Grade }\end{array}$ & $\begin{array}{l}\text { Lesion } \\
\text { Type }\end{array}$ & & & & & & & & & \\
\hline I & Subependymoma & Astrocytoma & 58/M & I & C & 2 & Ependymoma & STR & Yes & Alive \\
\hline I & Subependymoma & Nondiagnostic & $61 / F$ & I & $\mathrm{T}$ & 8 & Ependymoma & GTR & No & Alive \\
\hline II & Ependymoma & Glioma & 63/M & III & C & 4 & Ependymoma & STR & Yes & Alive \\
\hline II & Ependymoma & Astrocytoma & $59 / \mathrm{M}$ & III & C & 3 & Not available & GTR & No & Alive \\
\hline II & Ependymoma & Astrocytoma & 28/M & II & $\mathrm{T}$ & 5 & Nondiagnostic & PR & Yes & Alive \\
\hline II & Ependymoma & Glioma & $63 / F$ & III & C & 7 & Ependymoma & GTR & No & Alive \\
\hline II & Ependymoma & Glioma & 43/M & I & C & 3 & Ependymoma & GTR & No & Alive \\
\hline II & Ependymoma & Anaplastic astrocytoma & $39 / F$ & II & C & 3 & Ependymoma & GTR & No & Alive \\
\hline II & Ependymoma & Glioma & $26 / M$ & I & C & 1 & Ependymoma & GTR & No & Alive \\
\hline 1 & Pilocytic astrocytoma & Nondiagnostic & 38/F & 1 & $\mathrm{~T}$ & 1 & Nondiagnostic & GTR & Yes & Alive \\
\hline III & Anaplastic astrocytoma & Nondiagnostic & 59/M & IV & C & 2 & Nondiagnostic & STR & Yes & Dead \\
\hline III & Anaplastic astrocytoma & Ependymoma & $27 / F$ & III & C & 6 & Ependymoma & PR & Yes & Dead \\
\hline III & Anaplastic astrocytoma & Glioma & $47 / F$ & II & C & 4 & Astrocytoma & PR & Yes & Alive \\
\hline IV & Glioblastoma & Nondiagnostic & $54 / M$ & II & C & 3 & Nondiagnostic & Biopsy & Yes & Dead \\
\hline
\end{tabular}

$C=$ cervical; $T=$ thoracic.

* Tumor size was indicated with the number of vertebral bodies involved. 

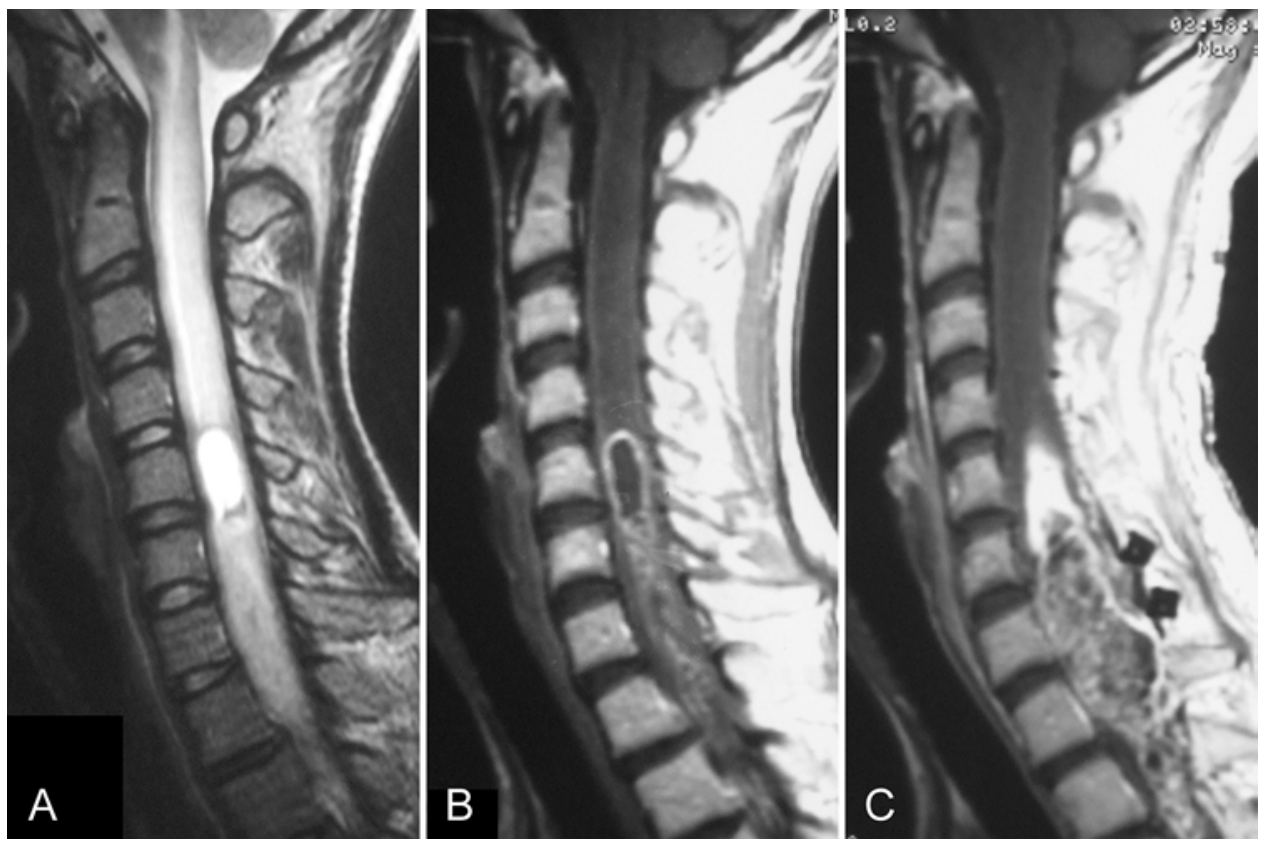

FIG. 2. Anaplastic astrocytoma misdiagnosed as ependymoma using frozen sections. A 27-year-old woman presented with a 6-month history of neck pain and a 1-month history of progressive tetraparesis. Sagittal T2-weighted MR image (A) showing congestion of the cervical spinal cord with an intramedullary cyst at the C5-6 level. Gadolinium-enhanced T1-weighted MR image (B) showing enhancement of the lower cervical spinal cord and cyst wall. The radiological diagnosis was suspected ependymoma. Although the intraoperative frozen-section diagnosis was ependymoma, the dissection plane between tumor and spinal parenchyma was poorly defined, particularly in the lower portion of the tumor. Although total resection was attempted after the frozen-section diagnosis, PR was performed. Radiotherapy and chemotherapy did not control progression of the tumor. Gadolinium-enhanced T1-weighted MR image (C) showing increasing enhanced tumor. The patient died 17 months after surgery.

racy of the frozen-section diagnosis. Furthermore, a correlation was not observed between each pathologist and the accuracy of the frozen-section diagnosis. The accuracy of the frozen-section diagnosis did not significantly change over the course of 23 years: 8 (67\%) of 12 cases were correctly diagnosed between 1993 and 2000, 11 (65\%) of 17 cases between 2001 and 2008, and $16(80 \%)$ of 20 cases between 2009 and $2016(\mathrm{p}=0.541)$.

\section{Preoperative MRI Diagnosis}

Seven of the 9 cases of ependymoma for which the frozen-section diagnosis disagreed were correctly diagnosed as ependymoma (Table 4). In contrast, only 1 of the 5 cases of astrocytoma for which the frozen-section diagnosis disagreed was correctly diagnosed as astrocytoma; 1 case was incorrectly diagnosed as ependymoma, and the other 3 cases had a nonspecific diagnosis.

\section{Progression-Free and Overall Survival}

Progression-free survival and OS were both significantly longer in cases of ependymoma than in cases of astrocytoma ( $p<0.001 ;$ Fig. 4). In the ependymoma group, 1 patient with WHO grade III anaplastic ependymoma died within the follow-up period. In the astrocytoma group, 4 patients with diffuse astrocytoma, 3 with anaplastic astrocytoma, and 1 with glioblastoma died. In 32 cases of ependymoma, GTR correlated with longer PFS ( $p=0.041)$. In the astrocytoma group, WHO grades tended to correlate with OS $(p=0.079)$, whereas the relationship between extent of resection and OS remained unclear.

\section{Discussion}

In the present study, the diagnostic accuracy of intraoperative frozen sections was found to be lower for spinal intramedullary spinal cord ependymoma than for intracranial CNS tumors. $3,4,13,15,16$ The sensitivity (72\%) and specificity (71\%) of a frozen-section diagnosis for the differentiation of ependymomas from astrocytomas were lower than expected. To the best of our knowledge, ours is the first study to investigate the frozen-section diagnosis of ISCTs.

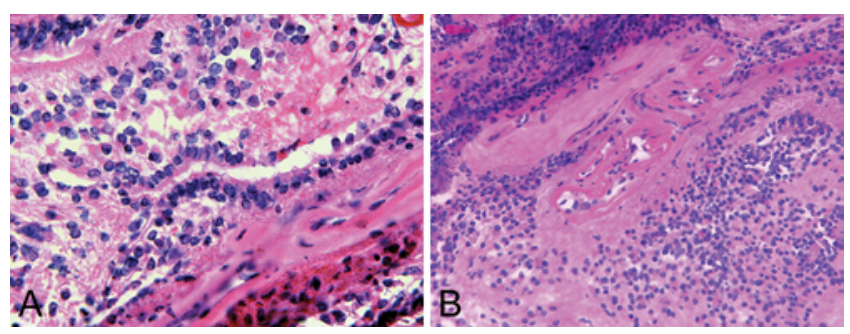

FIG. 3. Histological images of frozen sections showing an ependymal rosette $(A)$ and perivascular pseudorosettes $(B)$, which are consistent with ependymoma. $H \& E$, original magnification $\times 40(A)$ and $\times 20(B)$. Figure is available in color online only. 

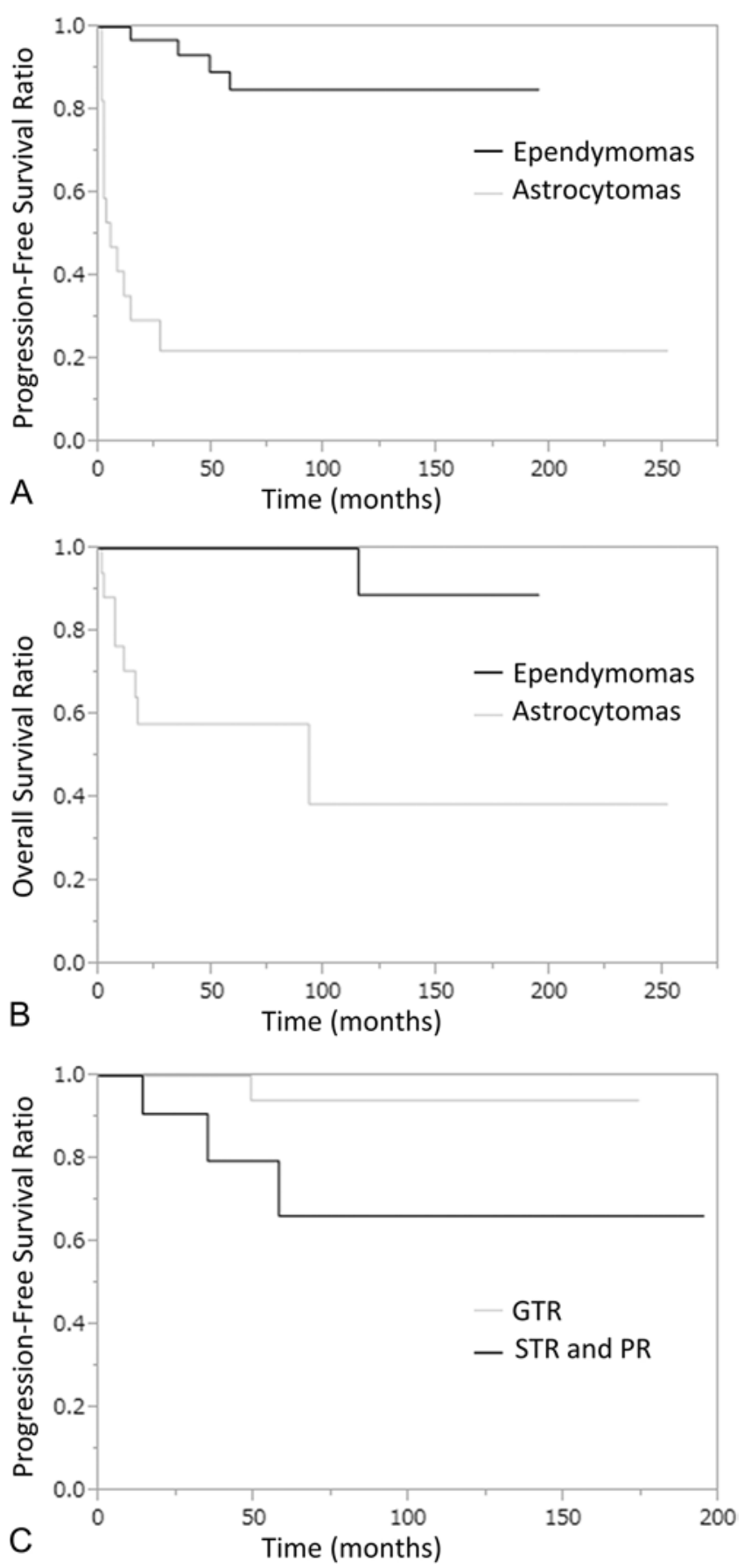

FIG. 4. A: Patients with ependymoma had significantly longer PFS than those with astrocytoma $(p<0.001)$. B: Patients with ependymoma had significantly longer OS than those with astrocytoma $(p<0.001)$. C: Among the patients with ependymoma, those who underwent GTR had significantly longer PFS than the patients with STR and PR ( $p=$ 0.041).

Our results suggest that an intraoperative frozen-section diagnosis alone is insufficient for the differential diagnosis of ISCTs. The most common cause of misdiagnosis has been considered to be a small tumor specimen size; however, we found no correlation between size of the specimens and accuracy of the frozen-section diagnosis among our cases. Colbassani et al. reported that, among 100 stereotactic brain biopsies, a sample volume of $2 \mathrm{~mm}^{3}$ was sufficient for diagnostic evaluation in most cases (67\%); however, the number of samples correlated with the diagnostic accuracy of frozen sections. ${ }^{4}$ The median sample volume in our case series was larger than $2 \mathrm{~mm}^{3}$. Additional samples from different portions of the tumor may contribute to increasing the diagnostic accuracy of frozen sections.

Histopathologically, ependymal rosettes and perivascular pseudorosettes are characteristic structures of ependymoma. ${ }^{17}$ Ependymal rosettes are more specific than perivascular pseudorosettes for the diagnosis of ependymoma. ${ }^{17}$ In the current study, the presence of perivascular pseudorosettes was the most significant parameter for the differentiation of ependymoma from astrocytoma. Therefore, careful evaluations of ependymal rosettes and perivascular pseudorosettes may contribute to increasing the accuracy of a frozen-section diagnosis.

In our case series, the presence of a dissection plane between tumor and spinal parenchyma was associated with the final diagnosis. ${ }^{5,7}$ Overall, regardless of the accuracy of the frozen-section diagnosis, GTR was achieved in 22 (69\%) of 32 cases of ependymoma but in only $2(12 \%)$ of the 17 cases of astrocytoma. The absence of dissection planes indicated to the neurosurgeon that the tumor was infiltrative. These results suggest that the frozen section and/or dissection plane helps guide neurosurgeons.

Regarding the neuroimaging diagnosis, most cases of ependymoma for which the frozen-section diagnosis disagreed were correctly diagnosed as ependymoma. In contrast, most cases of astrocytoma for which the frozen diagnosis disagreed had a nonspecific diagnosis. Therefore, preoperative neuroimaging was more beneficial for cases of ependymoma when the frozen-section diagnosis disagreed with the permanent diagnosis.

Neurosurgeons need to select a surgical strategy based on the frozen-section diagnosis as well as other multiple factors, such as clinical characteristics, preoperative imaging, and intraoperative findings of the tumor plane.

\section{Study Limitations}

This study has some limitations. It was a retrospective, single-institution analysis with a relatively small number of cases. However, we consider our study to be useful as a reference for neurosurgeons and neuropathologists involved in the diagnosis and treatment of spinal intramedullary spinal cord ependymomas and astrocytomas. A prospective multicenter study based on a larger number of cases needs to be performed.

\section{Conclusions}

Results of the present study demonstrated that the diagnostic accuracy of intraoperative frozen sections was lower for spinal intramedullary spinal cord ependymomas and astrocytomas than that for intracranial CNS tumors as reported in the literature. Surgical strategies need to be selected based on multiple factors, including clinical characteristics, preoperative imaging, frozen-section diagnosis, and intraoperative findings of the tumor plane. 


\section{Acknowledgments}

This work was supported by Grant No. H290601001 from the Tokyo Metropolitan Government.

\section{References}

1. Boström A, Kanther NC, Grote A, Boström J: Management and outcome in adult intramedullary spinal cord tumours: a 20-year single institution experience. BMC Res Notes 7:908, 2014

2. Celano E, Salehani A, Malcolm JG, Reinertsen E, Hadjipanayis CG: Spinal cord ependymoma: a review of the literature and case series of ten patients. J Neurooncol 128:377386, 2016

3. Chaturvedi S, Pant I, Dua R, Gupta S: Analyzing agreement patterns of intraoperative central nervous system lesion reporting according to type and grade. J Cytol 30:179-184, 2013

4. Colbassani HJ, Nishio S, Sweeney KM, Bakay RA, Takei Y: CT-assisted stereotactic brain biopsy: value of intraoperative frozen section diagnosis. J Neurol Neurosurg Psychiatry 51:332-341, 1988

5. Garcés-Ambrossi GL, McGirt MJ, Mehta VA, Sciubba DM, Witham TF, Bydon A, et al: Factors associated with progression-free survival and long-term neurological outcome after resection of intramedullary spinal cord tumors: analysis of 101 consecutive cases. J Neurosurg Spine 11:591-599, 2009

6. Kahan H, Sklar EML, Post MJ, Bruce JH: MR characteristics of histopathologic subtypes of spinal ependymoma. AJNR Am J Neuroradiol 17:143-150, 1996

7. Karikari IO, Nimjee SM, Hodges TR, Cutrell E, Hughes BD, Powers CJ, et al: Impact of tumor histology on resectability and neurological outcome in primary intramedullary spinal cord tumors: a single-center experience with 102 patients. Neurosurgery 76 (Suppl 1):S4-S13, 2015

8. Klekamp J: Spinal ependymomas. Part 1: intramedullary ependymomas. Neurosurg Focus 39(2):E6, 2015

9. Kucia EJ, Bambakidis NC, Chang SW, Spetzler RF: Surgical technique and outcomes in the treatment of spinal cord ependymomas, part 1: intramedullary ependymomas. Neurosurgery 68 (1 Suppl Operative):57-63, 2011

10. Louis DN, Perry A, Reifenberger G, von Deimling A, Figarella-Branger D, Cavenee WK, et al: The 2016 World Health Organization Classification of Tumors of the Central Nervous System: a summary. Acta Neuropathol 131:803-820, 2016

11. McCormick PC, Torres R, Post KD, Stein BM: Intramedullary ependymoma of the spinal cord. J Neurosurg 72:523532,1990
12. Minehan KJ, Shaw EG, Scheithauer BW, Davis DL, Onofrio BM: Spinal cord astrocytoma: pathological and treatment considerations. J Neurosurg 83:590-595, 1995

13. Plesec TP, Prayson RA: Frozen section discrepancy in the evaluation of central nervous system tumors. Arch Pathol Lab Med 131:1532-1540, 2007

14. Tobin MK, Geraghty JR, Engelhard HH, Linninger AA, Mehta AI: Intramedullary spinal cord tumors: a review of current and future treatment strategies. Neurosurg Focus 39(2):E14, 2015

15. Tofte K, Berger C, Torp SH, Solheim O: The diagnostic properties of frozen sections in suspected intracranial tumors: A study of 578 consecutive cases. Surg Neurol Int 5:170, 2014

16. Uematsu Y, Owai Y, Okita R, Tanaka Y, Itakura T: The usefulness and problem of intraoperative rapid diagnosis in surgical neuropathology. Brain Tumor Pathol 24:47-52, 2007

17. Wippold FJ II, Perry A: Neuropathology for the neuroradiologist: rosettes and pseudorosettes. AJNR Am J Neuroradiol 27:488-492, 2006

\section{Disclosures}

The authors report no conflict of interest concerning the materials or methods used in this study or the findings specified in this paper.

\section{Author Contributions}

Conception and design: Takai. Acquisition of data: Takai, Hongo. Analysis and interpretation of data: Takai, Hongo, Komori. Drafting the article: Takai, Hongo. Critically revising the article: Takai, Komori, Taniguchi. Reviewed submitted version of manuscript: all authors. Approved the final version of the manuscript on behalf of all authors: Takai. Statistical analysis: Takai, Hongo. Study supervision: Takai.

\section{Supplemental Information \\ Previous Presentations}

Portions of this work were presented in abstract form at the 32nd Annual Meeting of the Neurospinal Society of Japan, held in Osaka, Japan, on June 8-9, 2017.

\section{Correspondence}

Keisuke Takai: Tokyo Metropolitan Neurological Hospital, Tokyo, Japan.takai-nsu@umin.ac.jp. 